\title{
Application of Artificial Bee Colony Algorithm in Power Flow Studies
}

\author{
Kassim Al-Anbarri and Husham Moaied Naief \\ Department of Electrical Engineering, Faculty of Engineering, Mustansiriyah University, Bab Al-Muadham Campus, \\ 46049 Baghdad, Iraq
}

\section{A B S T R A C T}

Artificial bee colony $(A B C)$ algorithm is one of the important artificial techniques in solving general-purpose optimization problems. This paper presents the application of $A B C$ in computing the power flow solution of an electric power system. The objective function to be minimized is the active and reactive power mismatch at each bus. The proposed algorithm has been applied on typical power systems. The results obtained are compared with those obtained by the conventional method. The results obtained reveal that the $A B C$ algorithm is very effective for solving the power flow problem in the maximum loadability region.

Index Terms: Artificial Bee Colony, Maximum Loadability, Power Flow, Swarm Artificial Technique

\section{INTRODUCTION}

The power flow analysis is one of the important and extensively used studies in electrical power system engineering. It is considered a fundamental tool for many other power system studies such as stability, reliability, fault, and contingency study. The main objective of a power flow study is to find the bus voltages and the power flow in the transmission system for a particular loading condition. The steady-state performance of an electrical power system is described by a system of non-linear algebraic equations. These equations represent the active and reactive power balance. The inherent difficulty of the power flow problem is the task of obtaining analytical solutions to the power flow equations. An extensive research has been carried out since the latter half of the twentieth century [1], [2] to

\begin{tabular}{|l|l|}
\hline \multicolumn{2}{|c|}{ Access this article online } \\
\hline DOI: 10.21928/uhdjst.v1n1y2017.pp11-16 & $\begin{array}{l}\text { E-ISSN: 2521-4217 } \\
\text { P-ISSN: 2521-4209 }\end{array}$ \\
\hline
\end{tabular}

Copyright (C) 2017 Al-Anbarri and Naief. This is an open access article distributed under the Creative Commons Attribution Non-Commercial No Derivatives License 4.0 (CC BY-NC-ND 4.0) solve this problem. The solution of power flow problem has been based on numerical technique methods such as Gauss-Seidel [3], Newton-Raphson method [4]-[14], and fast-decoupled method [15]-[18]. Although some of these methods are widely used in power utilities, they are sensitive to the starting (guess) values. In some cases, especially in heavily loaded conditions, they fail to converge. It was found that the factors affecting the convergence of the previous methods are the $\mathrm{R} / \mathrm{X}$ ratio of the transmission systems and the singularity of the Jacobian matrix for a heavily loaded system. Different attempts have been done to improve the reliability of these methods [19], [20]. Artificial intelligence techniques had been applied to power flow study [21]-[23]. Recently, the fields of swarm intelligence have attracted many researches as a branch of artificial intelligence that deals with the collective behavior of swarms such as flocks of bird, colonies of aunts, schools of fish, and swarm of bees [24], [25]. The important features of swarm intelligence are selforganization, scalability, adaptation, and speed. The swarm intelligence techniques have been applied in many power system studies [26]-[28]. In this paper, the load flow problem is approached as an optimization problem using

Corresponding author's e-mail: alanbarri@yahoo.com 
swarm intelligence. The objective function is to minimize the power mismatch. This paper is organized as follows: Section 2 reviews the Newton-Raphson (NR) technique in solving load flow problem. The basics model of artificial bee colony $(A B C)$ is presented in section 3. Section 4 discusses the results obtained by applying the proposed algorithms on a typical system. Finally, section 5 presents the conclusion.

\section{POWER FLOW FORMULATION}

For $N$ bus electrical power system, the bus power $S_{i}$ can be expressed by the following equation:

$S_{i}=S_{G i}-S_{D i}$

$S_{i}=P_{G i}-P_{D i}+j\left(Q_{G i}-Q_{D i}\right)$

Where $P_{G i}$ is the active power generation at bus $i$

$P_{D i}$ is the active power demand at bus $i$

$Q_{G i}$ is the reactive power generation at bus $i$

$Q_{D i}$ is the reactive power demand at bus $i$

The current balance equation at bus $i$

$I_{i}=\frac{S_{i}^{*}}{V_{i}^{*}}=\sum_{k=1}^{N} Y_{i k} V_{k}$

Where $Y_{i k}$ is the $i$, $k^{\text {th }}$ element of bus admittance matrix

$V_{k}$ is the bus voltage at bus $k$.

By substituting (1) into the (2) and resolved the resulting equation into the following two real equations:

$$
\begin{aligned}
& P_{\mathrm{k}}=\sum_{i=1}^{N}\left|V_{k}\right|\left|V_{i}\right|\left|Y_{k i}\right| \cos \left(\gamma_{k i}+\delta_{\mathrm{i}}-\delta_{\mathrm{k}}\right) \\
& Q_{\mathrm{k}}=\sum_{i=1}^{N}\left|V_{k}\right|\left|V_{i}\right|\left|Y_{k i}\right| \sin \left(\gamma_{k i}+\delta_{\mathrm{i}}-\delta_{\mathrm{k}}\right)
\end{aligned}
$$

For $N$ bus power system, there are $2 N$ real non-linear algebraic equations similar to (3) and (4). These equations are non-linear function of the state variables $(|V|, \delta)$. The conventional technique to solve these equations is using a numerical technique. The most widely used method is NR method. This method is based on expanding the above equations by Taylor series. The compact linearized form of the above equations is as follows:

$$
\left[\begin{array}{c}
\Delta P_{i} \\
\Delta Q_{i}
\end{array}\right]=\left[\begin{array}{ll}
J_{P \delta} & J_{P|V|} \\
J_{Q \delta} & J_{Q|V|}
\end{array}\right]\left[\begin{array}{c}
\Delta \delta_{\mathrm{i}} \\
\Delta|\mathrm{V}|_{\mathrm{i}}
\end{array}\right]
$$

Where the left-hand side of (5) is the vector of power mismatch, which can be calculated as:

$$
\left[\begin{array}{c}
\Delta P_{i} \\
\Delta Q_{i}
\end{array}\right]=\left[\begin{array}{c}
P_{i}^{s p}-P_{i}^{c a l} \\
Q_{i}^{s p}-Q_{i}^{c a l}
\end{array}\right]
$$

The traditional algorithm for obtaining power flow solution is as follows:

1. Assume a guess values for the state variables (flat start $|\mathrm{V}|=1.0 \mathrm{pu} ; \delta=0$ )

2. Evaluate the vector of power mismatch and the elements of the Jacobian matrix

3. Calculate the vector of state variable disturbance

4. Update the state variables at the end of iteration

5. Check the absolute value of the elements of the vector of power mismatch, if it is less than a specified tolerance; calculate the line flow in each transmission line. Otherwise, go to step 2.

The previous algorithm works reliably in ordinary loading conditions. Unfortunately, it is found in some cases (e.g., heavily loaded conditions and high $\mathrm{R} / \mathrm{X}$ ratio system) that the above algorithm fails to converge. This is because of singularity of the Jacobian matrix. For this purposes, a swarm intelligence technique is presented to avoid the singularity of the Jacobian matrix.

\section{POWER FLOW ALGORITHM USING ABC METHOD}

The honey bees foraging behavior, learning, and memorizing characteristics have been attracted many researcher in the area of swarm intelligence. The pioneer work of Karaboga [24] which describes an $\mathrm{ABC}$ algorithm based on the behavior of honey bee is first attempt model in this aspect. One of the main features of $\mathrm{ABC}$ algorithm is its ability to conduct both global search and local search in each iteration.

According to the $\mathrm{ABC}$ algorithm, there are three categories of artificial bees in the colony. These are employed bees, onlookers bees, and scouts bees. The bee colony is divided into two halves, the first half of colony includes employed bees, and the second half includes the onlookers. The onlooker's bees are those waiting on the dance area in hive as a decision-maker for choosing the suitable food source. The employed bees are those collecting the nectar from food 
source. While the scout bees are those searching the food sources. The searching cycle in the $\mathrm{ABC}$ algorithm consists of the following steps [29]:

- At the initialization step, the bees select a set of food source positions randomly. After determining the nectar amount, the bees come to the hive to share the information with those waiting on the dance area.

- At the second step, the employed bees use the gained information to choose new food sources in neighborhood area after going to the old position, which is visited by themselves previously.

- At the third stage, the onlooker bee chooses a particular area for the food sources depending on the information given by the employed bees on the dance area.

To utilize the $\mathrm{ABC}$ algorithm, there are some control parameters that should be set [30]; they are number of variables, lower bound of variables (LB), upper bound of variables (UB), population size (colony size) (nPop), number of onlooker bees (nn Onlooker), maximum number of iterations (MaxIt) (the stopping criteria), abandonment limit parameter (Limit), and acceleration coefficient upper bound (A).

\section{A. Steps of ABC Implementation}

The steps of $\mathrm{ABC}$ can be outlined as follows [31]:

1. Generate a randomly distributed initial population solutions (food source positions).

2. Evaluate the population which represents the nectar quantity. The population of the positions (solutions) is subjected to iterated cycles, $C=1,2, \ldots, C_{\max }$, of the search processes of the employed bees, the onlooker bees and scout bees. Based on a probabilistic approach, the artificial employed or onlooker bee makes a change on the position (solution) in her memory for finding a new food source and tests the nectar amount (fitness value) of the new source (new solution).

3. Apply the roulette wheel selection (choose the best fit individuals).

4. Calculate the probability rate $(P i)$ related with solutions;

$$
P_{i}=\frac{\text { fit }_{i}}{\sum_{i=1}^{n p o p} f i t_{i}}
$$

The fitness values ( $f t$ ) are computed by the following expression:

$$
f_{i t}=\left\{\begin{array}{cc}
\frac{1}{1+f_{i}} & \text { if } f_{i} \geq 0 \\
1+\operatorname{abs}\left(f_{i}\right) & \text { if } f_{i}<0
\end{array}\right\}
$$

Usually, the value of $P_{i}$ is between $\{0,1\}$.

5. Find the new solutions for the onlookers depending on the probability $P_{i}$ related with the solutions.

6. Reapply roulette wheel selection.

7. Find the abandoned solution if exists, change it with new randomly generated solution.

8. Register the best solution achieved so far.

9. $C=C+1$ (until maximum cycle number is reached).

\section{B. ABC Implementation for Power Flow Study}

ABC optimization is applied to obtain the bus voltage magnitude $\left(\left|V_{i}\right|\right)$ and voltage phase angle $\left(\delta_{i}\right)$ by minimize the following objective function:

$\min f(\delta,|V|)$

Where,

$\delta=\left(\delta_{1}, \ldots \ldots \ldots \ldots, \delta_{n}\right)$

$|V|=\left(\left|V_{1}\right|, \ldots \ldots \ldots \ldots,\left|V_{n}\right|\right)$

This objective function is constrained by the inequalities $\mathrm{LB}$ and $\mathrm{UB}$.

$L B<|V|<U B$

$L B<\delta<U B$

The optimization process starts with setting the number of solutions (food sources) in $\mathrm{ABC}$ algorithm, which represents the number of flowers, the bees will reach to food sources, and then computes the nectar's quantity, the food sources are initialized using a random number generator.

The voltage magnitude and voltage phase angle are limited to the following range:

$0.5<\left|V_{i}\right|<1.05$

$-5<\delta_{i}<5$

The objective function $(f)$ that designed to determine the load flow problem using $\mathrm{ABC}$ algorithm is as follows:

$f=\sqrt{\sum \Delta P_{i}^{2}+\sum \Delta Q_{i}^{2}}$

Where $i=1,2,3, \ldots$ number of buses

In $\mathrm{ABC}$ algorithm, the objective function (fitness value) describes the quality of food source (solution). The food 
source that has the best quality will be registered in a memory as the best food source (solution) ever found. The neighborhood search process uses to obtain the best fitness value will continue by employed bees and onlookers. The fitness value will be computed for each new solution (food source), and the new solution (food source) that having the best fitness value will be the new reference in memory. The optimization process will continue to looking for the food source near to hive, which depending on the probability that computed previously from fitness value. The new solution (food source) after neighborhood search will be registered if its fitness is better. The optimization process will continue until reach to the best fitness value or reach to the maximum cycle number afterward the solution converges and the mismatch power is close to zero. The flow chart of $\mathrm{ABC}$ approach in load flow computation is shown in Fig. 1.

\section{RESULTS AND DISCUSSION}

The ABC algorithm is being applied to the 6-bus system as follows:

\section{A. Six Bus Test Power System with Normal Load}

The ABC method is applied to the 6-bus system with a particular normal loading condition [32]. The test system is shown in Fig. 2 consists of three generating stations and three load stations. After initialize the control parameters of $\mathrm{ABC}$ algorithm, each variable was initialized with random number using random number generator. The elements of power mismatch vectors $\Delta P$ and $\Delta Q$ are computed using Equation 6 . The best food source (load flow solution) will be selected by applying roulette wheel selection.

A comparison between the results that obtained from conventional (NR) with that found from $A B C$ algorithm is given in Table I. As shown from these tables, the results

\begin{tabular}{lccccc}
\multicolumn{5}{c}{ TABLE I } \\
The Bus Voltages using NR Method and ABC \\
Technique
\end{tabular}

ABC: Artificial bee colony, NR: Newton-Raphson obtained are identical. The final objective function value in $\mathrm{ABC}$ optimization process after 15000 iterations is $1.5902 \times 10^{-11}$. The performance of $\mathrm{ABC}$ algorithm to obtain the best solution is clarified by graph that was shown in Fig. 3 .

\section{B. Six Bus Test Power System with Heavy Load}

To simulate the heavy load condition, the load at bus 4, 5, and 6 is increased as shown in Appendix A. It is found that the conventional NR method is failed to converge. However, when the $\mathrm{ABC}$ algorithm is applied, the solution converges as shown in Table II. The final objective function value in ABC optimization process after 5000 iteration is $8.99 \times 10^{-4}$. The

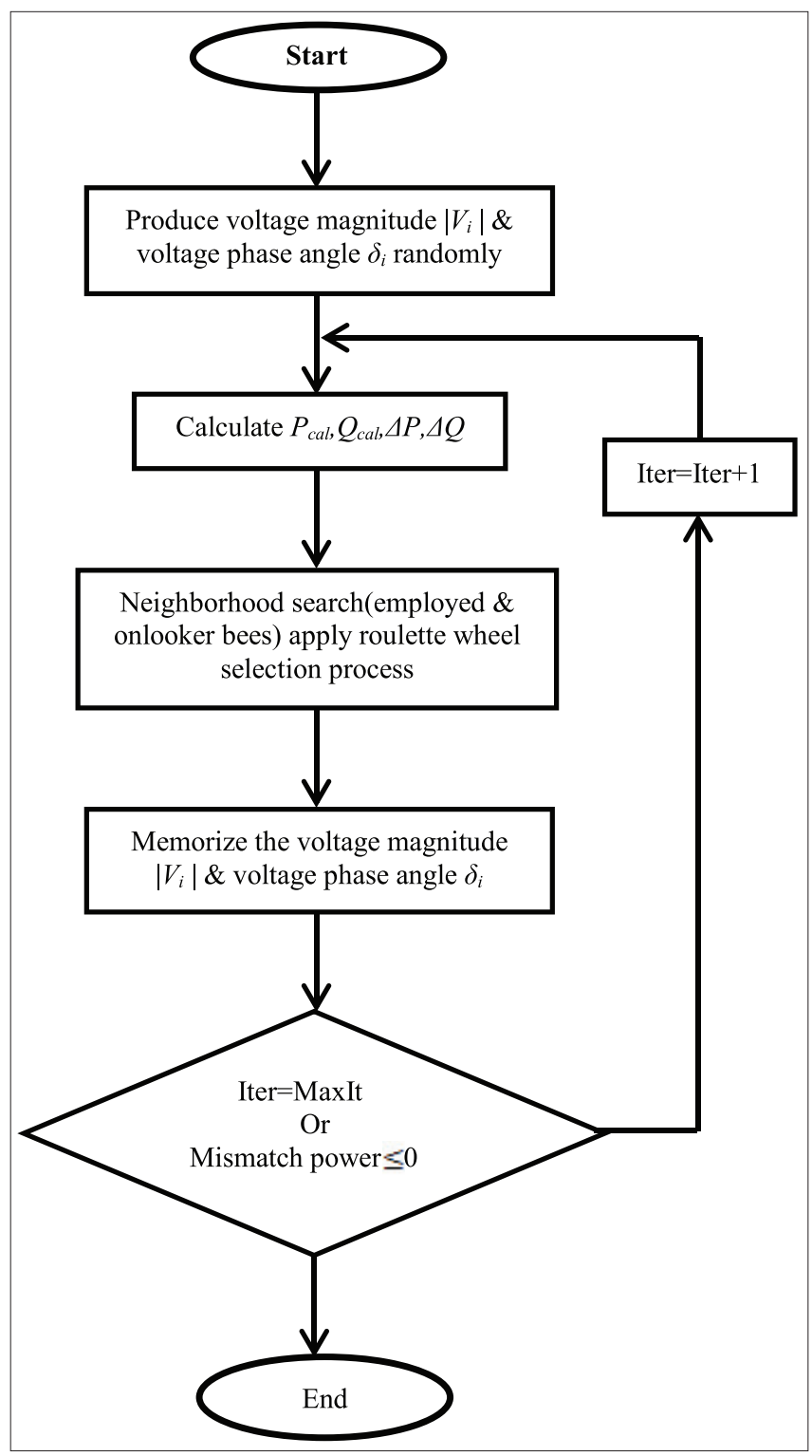

Fig. 1. Flow chart of application of artificial bee colony technique in power flow study 


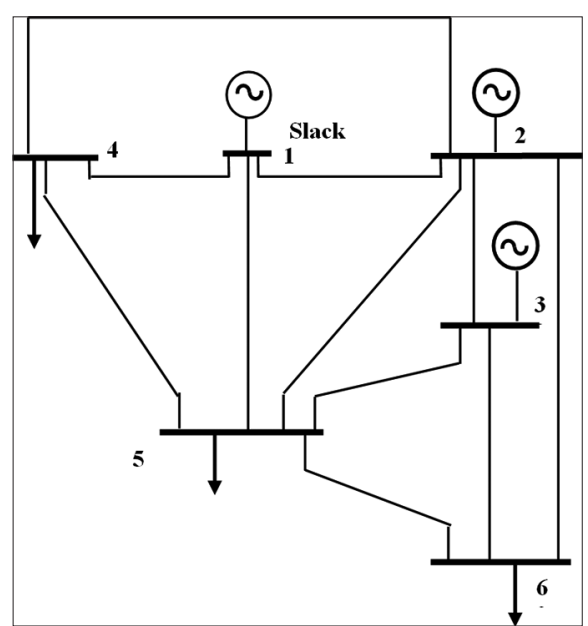

Fig. 2. Six bus test power system

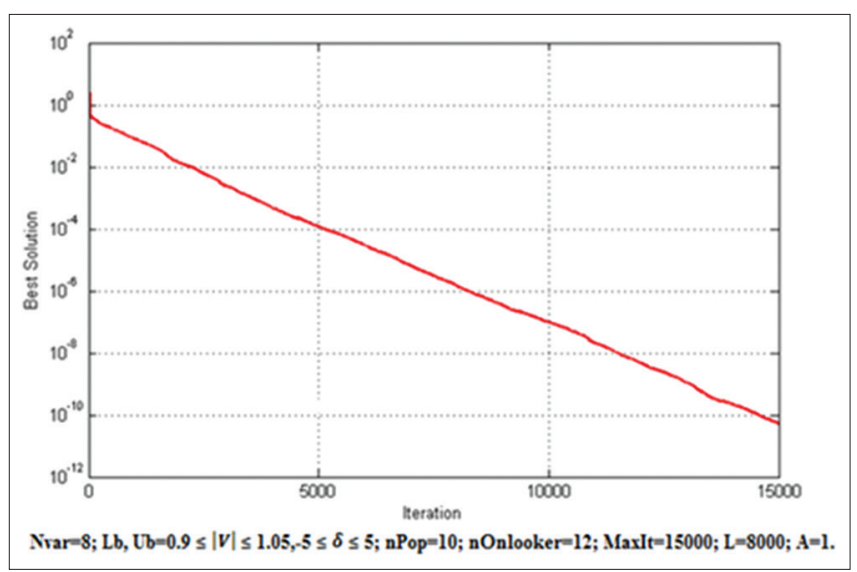

Fig. 3. The performance of artificial bee colony algorithm, best solution versus iteration

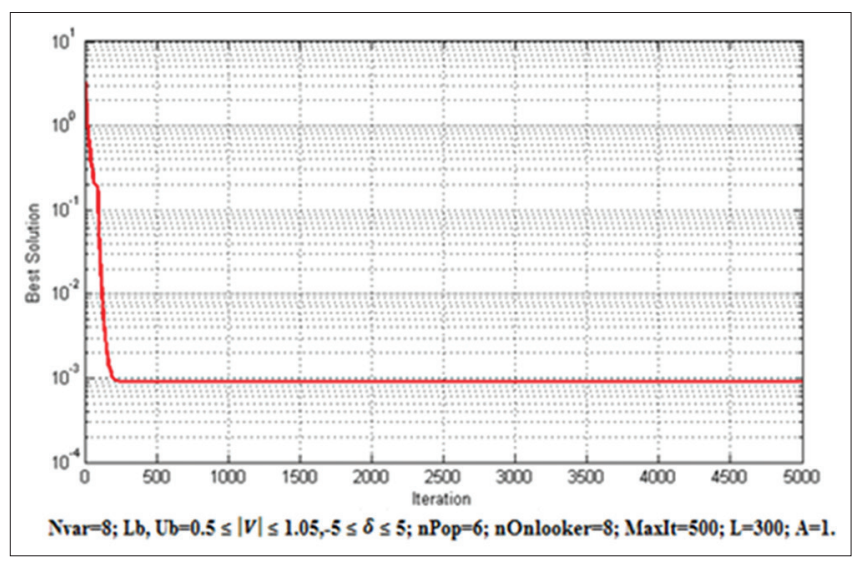

Fig. 4. The performance of artificial bee colony algorithm, best solution versus iteration

performance of $\mathrm{ABC}$ method to obtain the best solution is clarified by graph that was shown in Fig. 4.

The Bus Voltages for the Heavily Loaded Case
using ABC Technique where the NR Method Fails
to Solve

\section{CONCLUSION}

A meta-heuristic approach to solve power flow problem has been presented. The proposed algorithm is based on ABC technique which is considered to be one of the type of swarm intelligence techniques. The proposed algorithm is applied to the six bus system with different loading conditions, and the results obtained have been compared with the results of (NR) method. The main advantages of $\mathrm{ABC}$ algorithm are the flexibility of modeling, accuracy, strong convergence, and reliability, which considered reasonable and acceptable optimization process. In addition, the presented algorithm shows promising results regarding heavily loaded system.

\section{ACKNOWLEDGMENT}

The author would like to thank the Department of Electrical Engineering, Faculty of Engineering, Mustansiriyah University (www.uomustansiriyah.edu.iq), Baghdad, Iraq, for its support in the present work.

\section{REFERENCES}

[1] M. A. Laughton and M. W. H. Davies, "Numerical techniques in solution of power system load flow problems."Proceedings of the Institution of Electrical Engineers, vol. 111, No. 9, pp. 1575-1588, Sept. 1964.

[2] L. L. Freris and A. M. Sasson, "Investigation of the load-flow problem." Proceedings of the Institution of Electrical Engineers, vol. 115, No. 10, pp. 1459-1465, Oct. 1968.

[3] S. Moorthy, M. Al-Dabbagh and M. Vawser, "Improved phasecoordinate gauss-seidel load flow algorithm."Electric Power System Research, vol. 34, pp. 91-95, 1995.

[4] W. F. Tinney and C. E. Hart, "Power flow solution by Newton's method." IEEE Transactions on Power Apparatus and Systems, vol. PAS-86, pp. 1449-1460, Nov. 1967.

[5] B. Stott, "Effective starting process for Newton-Raphson load flows." Proceedings of the Institution of Electrical Engineers, 
vol. 118, no. 8. pp. 983-987, Aug. 1971.

[6] R. G. Wasley and M. A. Shlash, "Newton-Raphson algorithm for 3-phase load flow." Proceedings of the Institution of Electrical Engineers, vol. 121, No. 7, pp. 630-638, Jul. 1974.

[7] M. E. El-Hawary and O. K. Wellon, "The ALPHA-modified quasisecond order Newton-Raphson method for load flow solutions in rectangular form." Proceedings of the Institution of Electrical Engineers, vol. PAS-101, pp. 854-866, 1982.

[8] A. J. Flueck and H. D. Chiang, "Solving the nonlinear power flow equations with an inexact Newton method using GMRES." IEEE Transactions on Power Systems, vol. PWRS-13, No. 2. pp. 267273, May. 1998.

[9] M. D. Schaffer and D. J. Tylavsky, "A non-diverging polar form Newton based power flow." IEEE Transactions on Industry Applications, vol. 24, No. 5, pp. 870-877, 1998.

[10] V. M. da Costa, N. Martins and J. L. R. Pereira, "Developments in the Newton-Raphson power flow formulation based on current injections." IEEE Transactions on Power Systems, vol. 14, No. 4, pp. 1449-1456, Nov. 1999.

[11] Y. Xiao and Y. H. Song, "Power flow studies of a large practical power network with embedded FACTS devices using improved optimal multiplier Newton-Raphson method." European Transaction on Electrical Power, vol. 11, No. 4, pp. 247-256, Jul. Aug. 2001.

[12] M. Irving, "Pseudo-load flow as a starting process for Newton Raphson algorithm." International Journal of Electrical Power and Energy Systems, vol. 32, pp. 835-839, 2010.

[13] T. Kulworawanichpong, "Simplified Newton-Raphson power flow solution method." International Journal of Electrical Power and Energy Systems, vol. 32, pp. 551-558, 2010.

[14] S. M. R. Slochanal and K. R. Mohanram, "A novel approach to large scale system load flows Newton-Raphson method using hybrid bus." Electric Power Systems Research, vol. 41, pp. 219223, 1997.

[15] B. Stott, "Decoupled Newton load flow." IEEE Transactions on Power Apparatus and Systems, vol. PAS-91, pp. 1955-1959, 1972.

[16] B. Stott and O. Alsac, "Fast decoupled load flow." IEEE Transactions on Power Apparatus and Systems, vol. PAS-93, No. 3. pp. 859869, May. Jun. 1974.

[17] K. Behnam-Guilani, "Fast decoupled load flow: The hybrid model," IEEE Transactions on Power Systems, vol. PWRS-3, No. 2, pp. 734-742, May. 1988.

[18] A. V. Garcia and M. G. Zago, "Three-phase fast decoupled power flow for distribution networks." IEE Proceedings-Generation, Transmission and Distribution, vol. 143, No. 2, pp. 188-192, Mar. 1997.

[19] S. C. Tripathy, G. D. Prasad, O. P. Malik and G. S. Hope, "Load flow solutions for ill-conditioned power systems by a Newton-like method," IEEE Transactions on Power Apparatus and Systems, vol. PAS-101, pp. 3648-3657, Oct. 1982.

[20] D. Rajicic and A. Bose, "A modification to the fast decoupled power flow for networks with high R/X ratios." IEEE Transactions on Power Systems, vol. PWRS-3, No. 2, pp. 743-746, May. 1988.

[21] X. Yin, "Application of genetic algorithms to multiple load flow solution problem in electrical power systems." Proceedings of the $32^{\text {nd }}$ Conference on Decision and Control, Texas, pp. 3734-3738, 1993.

[22] W. L. Chan, A. T. P. So and L. L. Lai, "Initial applications of complex artificial neural networks to load-flow analysis." IEE ProceedingsGeneration, Transmission and Distribution, vol. 147, No. 6, pp. 361-366, Nov. 2000.

[23] P. Acharjee and S. K. Goswami, "Simple but reliable two-stage GA based load flow," Electric Power Components and Systems, vol. 36, pp. 47-62, 2008.

[24] D. Karaboga, "An idea based on honey bee swarm for numerical optimization," Technical Report-TR06, Erciyes University, Kayseri, Turkey, 2005.

[25] B. Akay and D. Karaboga, "A modified artificial bee colony algorithm for real-parameter optimization" Information Science, vol. 1, pp. 120-142, Jun. 2010.

[26] S. J. Huang, X. Z. Liu, W. F. Su, and T. C. Ou, "Application of enhanced honey-bee mating optimization algorithm to fault section estimation in power systems." IEEE Transaction on Power Delivery, vol. 28, no. 3, pp. 1944-1951, Jul. 2013.

[27] M. Afzalan and M. A. Taghikhani, "Placement and sizing DG using PSO and HBMO algorithms in radial distribution networks" International Journal of Intelligent System and Applications, vol. 4, no. 10, pp. 43-49, Sep. 2012.

[28] N. T. Linh and D. X. Dong, "Optimal location and size of distributer generation in distribution system by artificial bees colony algorithm" International Journal of Information and Electronics Engineering, vol. 3, no. 1, pp. 63-67, Jan. 2013.

[29] D. Karaboga and B. Basturk, "A powerful and efficient algorithm for numerical function optimization: Artificial bee colony(ABC) algorithm." Journal of Global Optimization, vol. 39, pp. 459-471, 2007.

[30] M. S. Kiran and M. Gündüz, "The analysis of peculiar control parameters of artificial bee colony algorithm on the numerical optimization problems." Journal of Computer and Communications, vol. 2, pp. 127-136, Mar. 2014.

[31] K. Al-Anbarri, A. H. Miri, and S. A. Hussain, "Load frequency control of multi-area hybrid power system by artificial intelligence techniques." International Journal of Computer Applications, vol. 138, no. 7, Mar. 2016.

[32] A. J. Wood and B. F. Wollenberg, Power Generation, Operation and Control, $2^{\text {nd }}$ ed, New York, NY: John Wiley \& Sons Ltd., 1996.

\begin{tabular}{|c|c|c|c|c|c|c|}
\hline \multicolumn{7}{|c|}{$\begin{array}{c}\text { APPENDIX A } \\
\text { Buses Data of 6-Bus Case with Heavily Loaded Condition }\end{array}$} \\
\hline Bus No. & |V|pu & $\delta\left(^{\circ}\right)$ & $P_{G}(M W)$ & $Q_{G}$ (MVAR) & $P_{D}(M W)$ & $Q_{D}$ (MVAR) \\
\hline 1 & 1.05 & 0 & 0 & 0 & 0 & 0 \\
\hline 2 & 1.05 & 0 & 80 & 0 & 0 & 0 \\
\hline 3 & 1.07 & 0 & 90 & 0 & 0 & 0 \\
\hline 4 & 1.0 & 0 & 0 & 0 & 255 & 130 \\
\hline 5 & 1.0 & 0 & 0 & 0 & 255 & 130 \\
\hline 6 & 1.0 & 0 & 0 & 0 & 255 & 152 \\
\hline
\end{tabular}

